\title{
Tradução
}

\section{Imaginario y representación en la formación del léxico colonial de Tocantins ${ }^{1}$ \\ Imaginário e representação na formação do léxico colonial do Tocantins}

Karylleila Santos ANDRADE*

\begin{tabular}{|c|c|}
\hline $\begin{array}{l}\text { RESUMEN: La lengua tupí es la } \\
\text { responsable por la formación de la } \\
\text { toponimia brasileña en los primeros } \\
\text { siglos después del "descubrimiento" de } \\
\text { Brasil. En Goiás, antigua Tierra de } \\
\text { Goyases, el período de las entradas y de las } \\
\text { bandeiras, expediciones conducidas } \\
\text { especialmente por los colonos paulistas y } \\
\text { las expediciones de los Jesuitas por los } \\
\text { ríos Araguaia y Tocantins, favorecieron la } \\
\text { formación de la toponimia en esa región. } \\
\text { Es cierto que por donde pasaban los } \\
\text { pueblos indígenas, que hablaban lenguas } \\
\text { del tronco tupí, denominaban la realidad } \\
\text { circundante a fin de demarcar los } \\
\text { espacios del paisaje local (elementos } \\
\text { físicos: ríos, arroyos, sierras etc. y } \\
\text { elementos humanos y/o culturales } \\
\text { (campamentos, pueblos, juzgados, etc.) } \\
\text { con diversos intereses, entre ellos, la } \\
\text { conquista de territorios. El presente } \\
\text { artículo tiene como propuesta ofrecer } \\
\text { lecturas sobre la formación de la } \\
\text { toponimia colonial en la Provincia de }\end{array}$ & $\begin{array}{l}\text { ABSTRACT: The tupi language is } \\
\text { responsible for the formation of Brazilian } \\
\text { Toponymy in the first centuries after the } \\
\text { "finding" of Brazil. In Goiás, former Land } \\
\text { of Goyases, the period of entradas } e \\
\text { bandeiras expeditions, performed } \\
\text { especially by São Paulo settlers, and the } \\
\text { expeditions of Jesuits on the Araguaia } \\
\text { and Tocantins rivers, promoted the } \\
\text { toponymic formation in this region. The } \\
\text { truth is that where indigenous people } \\
\text { passed and spoke tupi languages, they } \\
\text { named the surrounding reality in order to } \\
\text { demarcate the areas of the local landscape } \\
\text { (physical elements: rivers, streams, } \\
\text { mountains etc. and human and/or } \\
\text { cultural elements: camps, villages, } \\
\text { parishes, etc.) with various interests, } \\
\text { including the conquest of territories. This } \\
\text { article proposes to offer readings about } \\
\text { colonial toponymic formation in the } \\
\text { Province of Goiás, bearing in mind the } \\
\text { people of the region, particularly, by the } \\
\text { Araguaia and Tocantins rivers. Moreover, }\end{array}$ \\
\hline
\end{tabular}

${ }^{1}$ Este texto é uma tradução do artigo já publicado na revista Filologia e Linguística Portuguesa, v. 19 n. 2 (2017), disponível no link http://www.revistas.usp.br/flp/article/view/121997. Acesso em: 29 set 2020. A tradução foi autorizada pelo editor da revista FLP.

* Professora da UFT. ORCID: https://orcid.org/0000-0001-6920-9206. karylleila@gmail.com 


\begin{tabular}{|c|c|}
\hline $\begin{array}{l}\text { Goiás teniendo en vista que el } \\
\text { poblamiento de la región se dio, } \\
\text { particularmente, por los ríos Araguaia y } \\
\text { Tocantins. Además, tenemos la intención } \\
\text { de presentar una posible lectura de esa } \\
\text { formación a partir de datos documentales } \\
\text { de la "existencia" del pueblo indígena } \\
\text { denominado Tocantins. Los } \\
\text { procedimientos metodológicos utilizados } \\
\text { fueron la investigación bibliográfica y } \\
\text { documental (mapas y documentos de los } \\
\text { siglos XVI, XVII y XVIII). Los autores } \\
\text { Sampaio (1987), Flores (2009), Casal } \\
\text { (1845), Ferreira (1960), Palacin, Garcia e } \\
\text { Amado (1995) se toman como fuentes de } \\
\text { la investigación bibliográfica. }\end{array}$ & $\begin{array}{l}\text { we intend to present a possible reading of } \\
\text { this formation stem from documentary } \\
\text { data of the "existence" of indigenous } \\
\text { people named Tocantins. Methodological } \\
\text { procedures used were bibliographical } \\
\text { and documental research (maps and } \\
\text { documents from the XVI, XVII and XVIII } \\
\text { centuries). Authors as Sampaio (1987), } \\
\text { Flores (2009), Casal (1845), Ferreira (1960, } \\
\text { 1977), Palacin, Garcia and Amado (1995) } \\
\text { supported the bibliographical research. }\end{array}$ \\
\hline $\begin{array}{l}\text { PALABRAS CLAVE: Léxico. Toponimia. } \\
\text { Ríos Araguaia y Tocantins. Tocantins } \\
\text { Colonial. }\end{array}$ & $\begin{array}{l}\text { KEYWORDS: Lexicon. Toponymy. } \\
\text { Araguaia and Tocantins rivers. Colonial } \\
\text { Tocantins. }\end{array}$ \\
\hline
\end{tabular}

\section{Introducción}

Las entradas y las bandeiras que cortaron los sertões ${ }^{2}$ en los siglos XVI, XVII y XVIII dejaron registros en documentos y guiones referidos al topónimo Tocantins. Ferreira (1960, p. 259) cita a Bento Maciel Parente, capitán mayor de la Provincia de Pará, el día 20 de abril de 1625, con el pasaje de una "memoria" (énfasis del autor) que fue enviada al rey:

Demás, destas Capitanias se pueden demarcar otras, entre el Rio de las Amaçonas, y el Gran Pará, y por cima de la Província de los Tocantines, por ser el Rio muy navegable, y las tierras fertiles, que se entiende que daran trigo, y vino, y otras cosas de Espana, como se dan en el Nuevo

\footnotetext{
${ }^{2}$ Región del interior, de vegetación esparza y suelo arenoso y salitroso, sujeto a sequías periódicas, con población escasa y lejos de los centros urbanos, donde la ganadería se sobrepone a las actividades agrícolas.
} 
Reino de Granada ${ }^{3}$ que allí es vecino, y esta en la misma altura: también por aquí ay muchas minas, como en el Nuevo (Reino de Granada), y quiçá mas ricas (FERREIRA, 1960, p. 259)

Ferreira (1960) resalta que Parente no deja claro que el río que cruza la región (Provincia de los Tocantins) tuviese esa misma denominación. Sin embargo, “entonces los exploradores en Pará probablemente ya llamaban al río Tocantins, por una nación indígena que vivía en la región" (p. 259). En cuanto a la "nación indígena" de mismo nombre, no hay documentos aún que comprueben su existencia. Lo que se puede decir es que el río Tocantins fue el nombre adoptado por franceses, jesuitas portugueses y mestizos del norte, aún en la colonia, para el río que desciende al norte y desemboca en el río Pará. Como muestra Flores (2009, p. 29), varios fueron los grupos que tenían denominaciones próximas al nombre Tocantins. "Esos pueblos eran los Tacamedus (habitaban las orillas del río Tocantins), los Tacandiras (los mismos que los Tocandiras), los Tacanhunas, los Tocanos y los Tucanos, y otros" (FLORES, 2009, p. 31). De hecho, lo que se percibe es una aproximación a la grafía, pero, como ya fue dicho antes, es una cuestión académica aún en abierto, una vez que hay diversas imprecisiones al respecto del nombre del río. Aún según Flores (2009, p. 31), “En los primeros itinerarios coloniales, o en los testamentos e inventarios de los bandeirantes de São Paulo, varias designaciones hacían referencia a la misma región donde se encuentra el río". En tales documentos, la autora revela que el nombre Tocantins tenía una relación muy fuerte con la lengua hablada por diversos grupos indígenas de la época, los cuales habitaban la región a la margen del río. Es cierto que fueron ellos propios que guiaron y dieron diversas informaciones a los bandeirantes en sus andanzas por los sertões, como también a los misionarios venidos de la Amazonia.

\footnotetext{
${ }^{3}$ Ferreira (1960, p. 259) señala que Parente, como todos los demás en ese momento, creía que el Perú (Reino de Granada) tenía fronteras en la región de Tocantins, es decir, el río Paraupava. Y que había mucho oro en esa región.
} 
Aun sobre una posible existencia de un pueblo llamado "Tocantins", Vieira (1746), Tomo III de las Cartas, apunta: “Lo que se ha dicho sobre las Poquiguáras, también se entiende de las Catingas, y con mucho mayor razón, porque están más arriba de los Tocantins, no solo cerca de sus tierras, sino casi dentro de ellas"' (p. 8586). Una interpretación posible de esa citación es que Vieira estuviese hablando de los pueblos "Poquiguaras", "Catingas" y de los dichos "Tocantins". Otro estudioso al referirse a la existencia de un grupo llamado Tocantins es Castro (1941, p.124): “Tocantins o Tucantins, 'nariz de tucán', nombre de una tribu que habitaba las orillas del río". Vieira (1735), Tomo I de las Cartas, aun hace referencia a la misión que le fue dada por el Capitán Mayor de recorrer el Río de Tocantins:

Decepcionado con esta Misión, o engañado por ella, me fui hacia Pará con los Curas que había detenido, y tratando de pasar al Rio das Almazonas, me ofreció el Capitán jefe de allí N. do N. otra Misión al

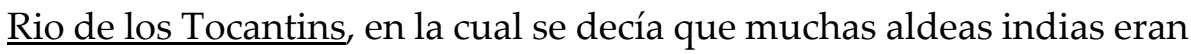
inestables para que se bajara hasta allí (VIEIRA, 1735, p. 62) (subrayado nuestro).

El siguiente documento, localizado en el Archivo Ultramarino de Lisboa, con fecha de 21 de junio de $1647^{5}$, Provincia de Pará, indica la existencia de los probables "indios Tocantins". Se trata de un requerimiento dirigido al proveedor de la Hacienda Real del Pará.

REQUERIMIENTO del capitán jefe de Pará, Sebastião de Lucena de Azevedo, al rey [D. João IV], solicitando un traslado 1 de las órdenes y bandos del Gobernador del Estado de Maranhão, Francisco Coelho de Carvalho, sobre los asuntos de indios (tocantins, tupinambás, camutás

\footnotetext{
${ }^{4}$ Los Potiguara viven hoy en los estados de Paraíba y Ceará. Datos disponibles en el sitio < http://pib.socioambiental.org/pt/povo/potiguara/934>. Acceso en: 18 feb. 2015.

${ }^{5}$ Información de la AHU, disponible en: http://actd.iict.pt/eserv/actd:CUc013/CU-Para.pdf. Acesso en: 28 maio 2015.
} 
y los esclavos del pirata Bandergoss) y del gobierno de la capitanía (AHU_CU_013, Cx. 1, D. 67) (subrayado nuestro). ${ }^{6}$

A continuación, se presenta parte del documento (Figura 1) y, luego, su transcripción ${ }^{7}$ conforme a la grafía de la época.

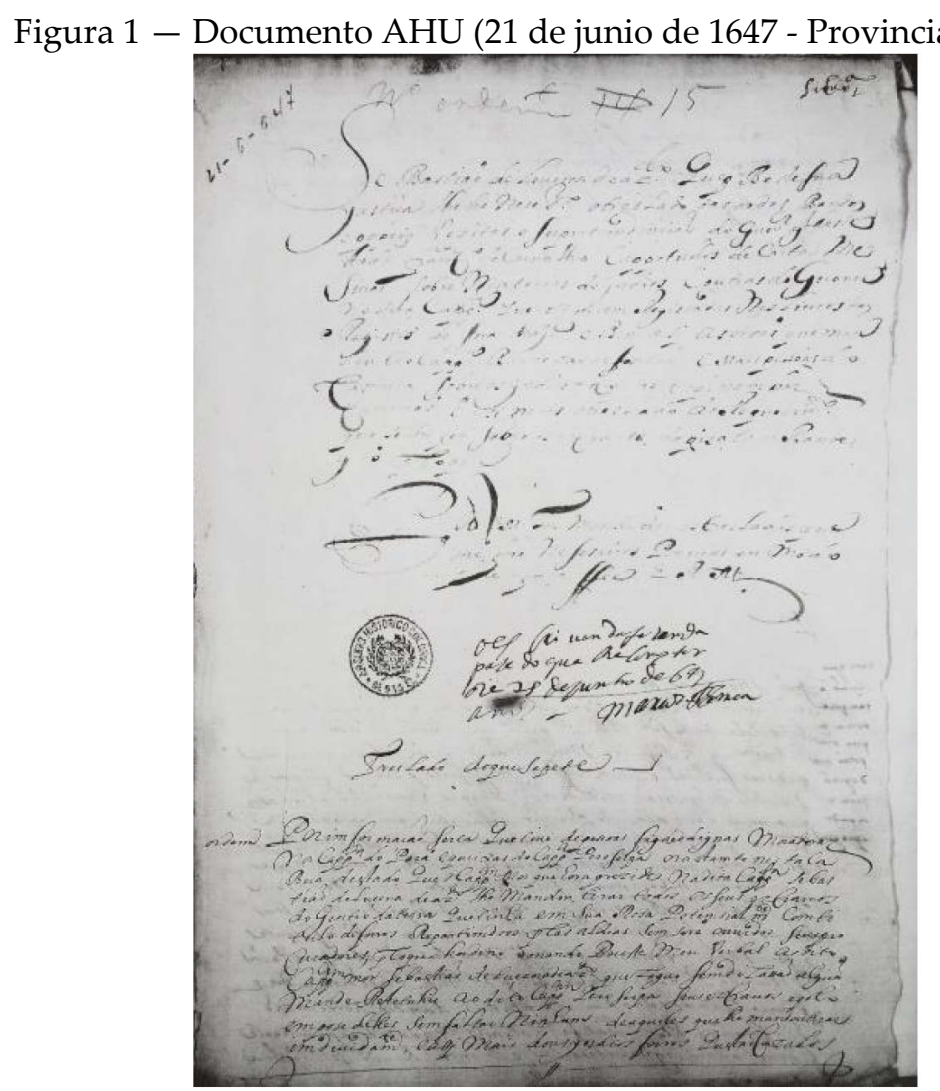

Fuente: Imagen: Reproducción facsimilar del documento bajo la cuota AHU/Lisboa_CU_013, Cx. 1, D.

67.

\footnotetext{
${ }^{6}$ Traslado es una copia de un texto original, y, en términos más específicos, es una copia certificada por una autoridad pública, en este caso el escribano de la Proveeduría del Tesoro, Brás da Silveira, en el que escribe: "Todo está concertado para el traslado de los mismos (es decir, el traslado de los documentos originales) por mí, escribano del Tesoro", por lo que no cobró emolumentos "Gratis".

7 Transcripción adaptada a la ortografía actual: Sebastião de Lucena de Azevedo que por el bien de su justicia necesita el traslado de órdenes, bandos y papeles, visitas y superintendencias del gobernador general de este estado Francisco Coelho de Carvalho, capítulos de cartas misivas sobre asuntos de indios y otros del gobierno de esta capitanía que estén registrados en los libros de los registros de Su Majestad, del mismo modo las órdenes que envió al capitán Baltasar de Fontes y a más personas de Camutá respecto a los indios tocantins, tupinambás y camutás $\mathrm{y}$, del mismo modo, el traslado de la solicitud que se le hizo sobre los esclavos del pirata u Bandergoos [?], por lo que Pide a Vuestra Merced le mande dar los traslados que le sean necesarios por los caminos de modo que dé fe Y Recibirá Merced. El escribano del tesoro pase de lo que le conste hoy 25 de junio de 1647 años. Firma) Marcos Gonçalves Correa.
} 
Figura 2 - Transcripción del documento AHU (21 de junio de 1647 - Provincia de Pará).

Sebastião de Lucena de Azeuedo que para bem de sua yustiça lhe he nesessario o treslado das ordes bandos e papeiz vezitas e supretemdencias do guouernador geral deste estado Francisco Coelho Silueira de Carualho cappitullos de cartas messiuas sobre materias de yndios e

outras do guouerno desta cappitania que esteuerem registadas nos liuros dos registos de Sua Magestade e bem asj as ordens que mandou ao cappitam Baltezar de Fontes e mais pessoas do Camuta sobre os

yndios tocantins topinambaz e camutás e asi mais o treslado do requerimento que se lhe fez sobre os escrauos do pirata u Bandergoos [?] pelo que Pede a Vossa Merce lhe mande dar os treslados que lhe forem nesesarios por uias en modo que faça ffee $E$ Recebera Merce $\mathrm{O}$ escriuam da fazenda pase do que lhe constar oje 25 de Junho de 647 anos.

Ass) Marcos Gonsalues Correa

Treslado do que se pede.

Fuente: Imagen: Transcripción del facsimilar del documento bajo la cuota AHU/Lisboa_CU_013, Cx. 1, D. 67 (adaptado).

La transcripción anterior sugiere hacer referencia a los dichos "índios tocantins" en el siguiente pasaje: “las órdenes que envió al Capitán Baltezar de Fontes y más personas de Camuta sobre los indios tocantins topinambaz y camutás" (énfasis agregado). De la lectura, se puede concluir que Sebastião Lucena de Azevedo solicita al proveedor de la Hacienda Real que mande trasladar todas las órdenes y documentos (registrados en los libros de la secretaría del gobierno del estado) que el gobernador Francisco dispuso sobre los indios tocantins, tupinambás y camutás, y además el traslado del requerimiento sobre los esclavos del pirata, para que, con esos traslados, requiera al rey y así obtenga justicia. El proveedor de la Hacienda Marcos Gonçalves despacha o decide el 25 de junio que el escribano de la hacienda Brás da Silveira pase los dichos traslados. Basado en la transcripción del texto, el documento demuestra la existencia de los indios tocantins en aquella región. Sin embargo, en el conjunto de las provisiones de que se compone el traslado, tan sólo hay referencias al río Tocantins y a los indios naturales que en él habitan. 


\section{La toponimia en Goiás en el siglos XVIII y XIX}

De la familia tupí-guaraní, Tronco Macro-Tupí los portugueses aprendieron la lengua, adquirieron hábitos y costumbres, recorrieron sus senderos, pero, sobre todo, asimilaron la noción de unidad del país ya habitado y conocido por los indígenas. La influencia del tupí en São Paulo fue constante durante la época de las bandeiras, cuya región ya era marcada por el mestizaje. Hasta mediados del siglo XVIII, la lengua general era más usada que el portugués. No hay duda de que la "lengua" de las bandeiras marca la toponimia identificada por los bandeirantes, incluso en aquellos en que se encontraban grupos indígenas no tupí.

Mapa 1 -Mapa de los Sertões que se extienden de mar a mar entre las capitanías de S. Paulo,

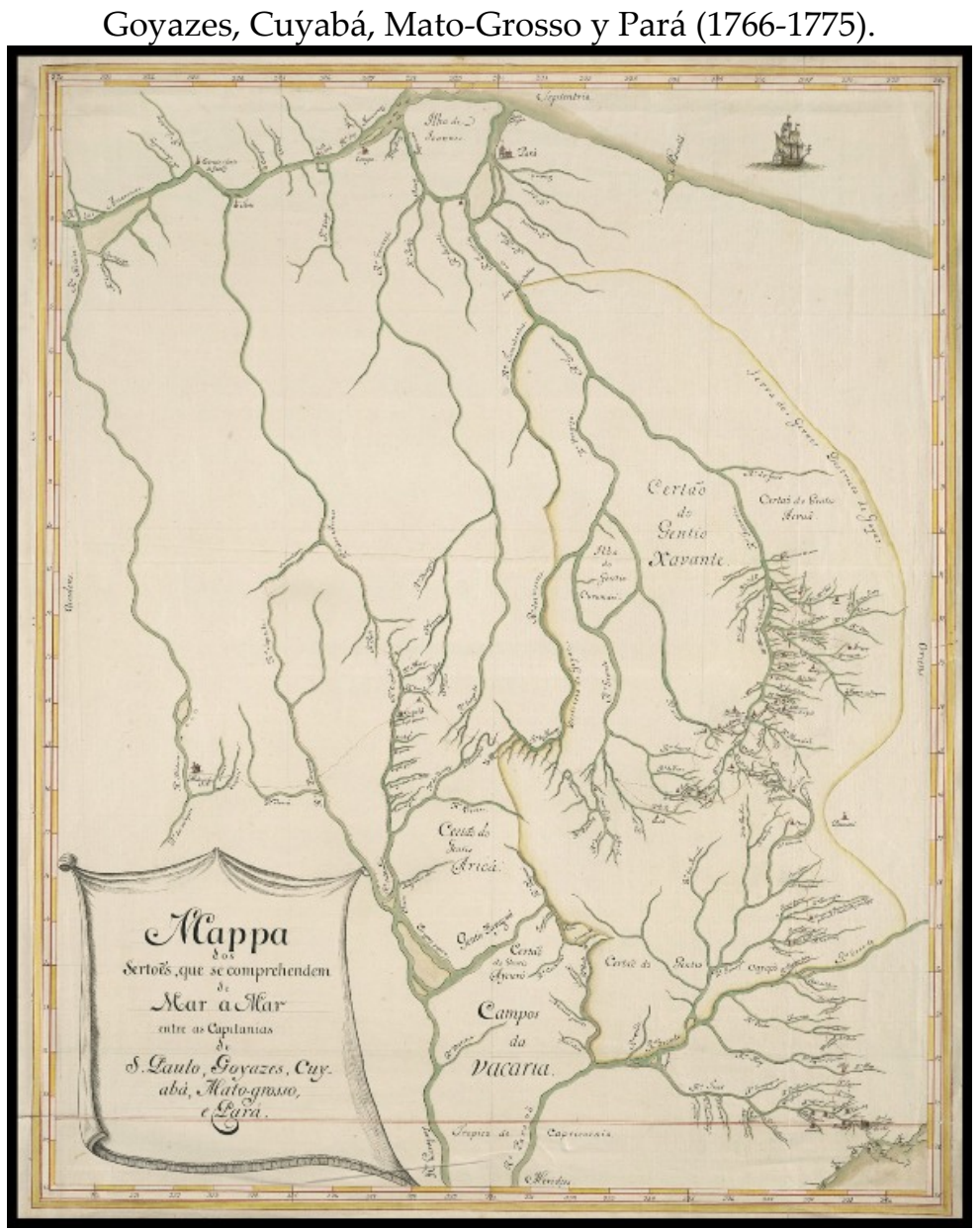

Fuente: Biblioteca Nacional - Disponible en: .www.bn.br / bndigital. Accedido el: 2 nov. 2018. 
Según Sampaio (1987), “Las bandeiras sólo hablaban el tupí. Y si, por doquier que ingresaran, extendían los dominios de Portugal, no propagaban su lenguaje, que, sólo más tarde, se introdujo con el progreso de la administración, con el comercio y las mejoras" (p. 71). El hecho es que, por todo el sertão, el tupí predominó en la formación de la Toponimia brasileña. Recibían nombres de origen tupí los lugares, elementos principalmente de procedencia de la naturaleza circundante, aunque no hubiese rasgos de cualquier pueblo tupí. La conservación ocurriría a partir del "descubrimiento" cuyo proceso de consolidación se haría efectivo con el tiempo o, incluso, con el registro en documentos de la época. "Y así es que, en la Meseta Central, donde dominan pueblos de otras razas, las denominaciones de los valles, ríos y montañas e incluso poblaciones son en su mayoría de la lengua general"' (SAMPAIO, 1987, p. 71). Es lo que podemos identificar actualmente en la toponimia del estado de Tocantins, en los nombres de los municipios: Tupirama, Tupiratins, Tocantínea, Tocantinópolis, Gurupi, Cariri, Dueré, Itaguatins, Itacajá, Goiatins, Araguaína, Araguatins, Araguaçu, Arapoema, y otros.

No prevalecieron solamente nombres de origen indígena en la formación de la antigua Provincia de Goiás, hoy, región que ocupa el estado de Tocantins. La mirada atenta de los sertanistas ${ }^{8}$, exploradores de la naturaleza y ávidos por encontrar metales preciosos, bautizaba los lugares con nombres que vertían sus propias impresiones de la realidad física circundante (el litotopónimo Arraial $^{9}$ da Barra, el dimensiotopónimo: Arraial Meia-Ponte y el geomorfotopónimo: Arraial da Chapada), demarcaban especificidades de habitantes o de personas importantes políticamente para la comunidad (el sociotopónimo: Arraial Ferreiro y el antropotopónimo: Arraial Cavalcante) o, incluso, se servían de simbologías del catolicismo europeo (los hagiotopónimos: Arraial de Santana y Arraial de Santa Luzia).

\footnotetext{
${ }^{8}$ Persona que explora o conoce bien los sertões.

${ }_{9}^{9}$ Pequeña población.
} 
Brandão (1978, p.26) relata que la bandeira de Bartolomeu Bueno da Silva (el hijo), durante el viaje a las tierras de goyazes en búsqueda de oro, encontró

un río que llamaron Perdición por estar completamente perdidos allí. Este río entraba en otro brazo similar al primero, que llamaron los Aráes: más adelante descubrieron un tercer brazo, donde había una gran abundancia de oro, por lo que lo llamaron rio Rico". [...] después de su segundo viaje, 1726, "Bartolomeu Bueno, muy satisfecho, inmediatamente trató de levantar un establecimiento al lado de un río, que más tarde llamaron Rio Vermelho, porque el agua siempre es del color de Barro, a causa de los trabajos mineros (BRANDÃO, 1978, p.2627) (subrayado nuestro).

A respecto del topónimo $\underline{\text { Vila Boa de Goiás }}{ }^{10}$, Souza $(1978$, p. 85) describe que

El Sr. Don Luiz Mascarenhas sucedió en el gobierno de S. Paulo, y [...] se dirigió a Goiás con gran comitiva de oficiales militares el 25 de julio de 1739; demarcó el lugar de la villa que vino a crear, a la que llamó Vila Boa de Goiás, en atención a Bueno, su descubridor y al gentío de Goyaz [...] (SOUZA, 1978, p. 85) (subrayado nuestro).

Casal (1845, p. 276) observa que la nación indígena que culminó en el nombre de la provincia de Goyaz, no era la única que vivía en la región: “al norte de ella vivía el Gentío Crixá, del cual los conquistadores nombrarán el río (Río Crixá), que cruzaba su territorio" (énfasis agregado). Del nombre Rio Vermelho, el viajero Pohl hace

\footnotetext{
10 Notas toponímicas: Según Ferreira (1960, p.319), el nombre Goiás aparece, por primera vez, con la bandeira de Domingos Rodrigues (1596-1600). El sertanista apresó a indios de la nación Goiás en el sertão del río Paraupava. Señala que esos indios son ciertamente los mismos indios reportados en la descripción del viaje de Pedro Teixeira por el Amazonas, en 1637. En cuanto al topónimo dado a la Capitanía de Goiás, concluye que no fue gracias a la historia de Anhanguera, quien afirma haber encontrado indios de esa nación en 1726, como lo afirma la tradición de Sousa en 1812. La región se conocía anteriormente como "sertão dos Goiás", que después se substituyó por "minas dos Goiás". Y de ahí, surgió el nombre de la Capitanía de los Goiás.
} 
observaciones sobre su origen: "El Rio Vermelho, que toma su nombre del color de sus aguas rojas" $(P O H L, 1976$, p. 140) (subrayado nuestro).

Mapa 2 - Capitanía de Goyaz (Villas, Arraiais do ouro, Caminos).

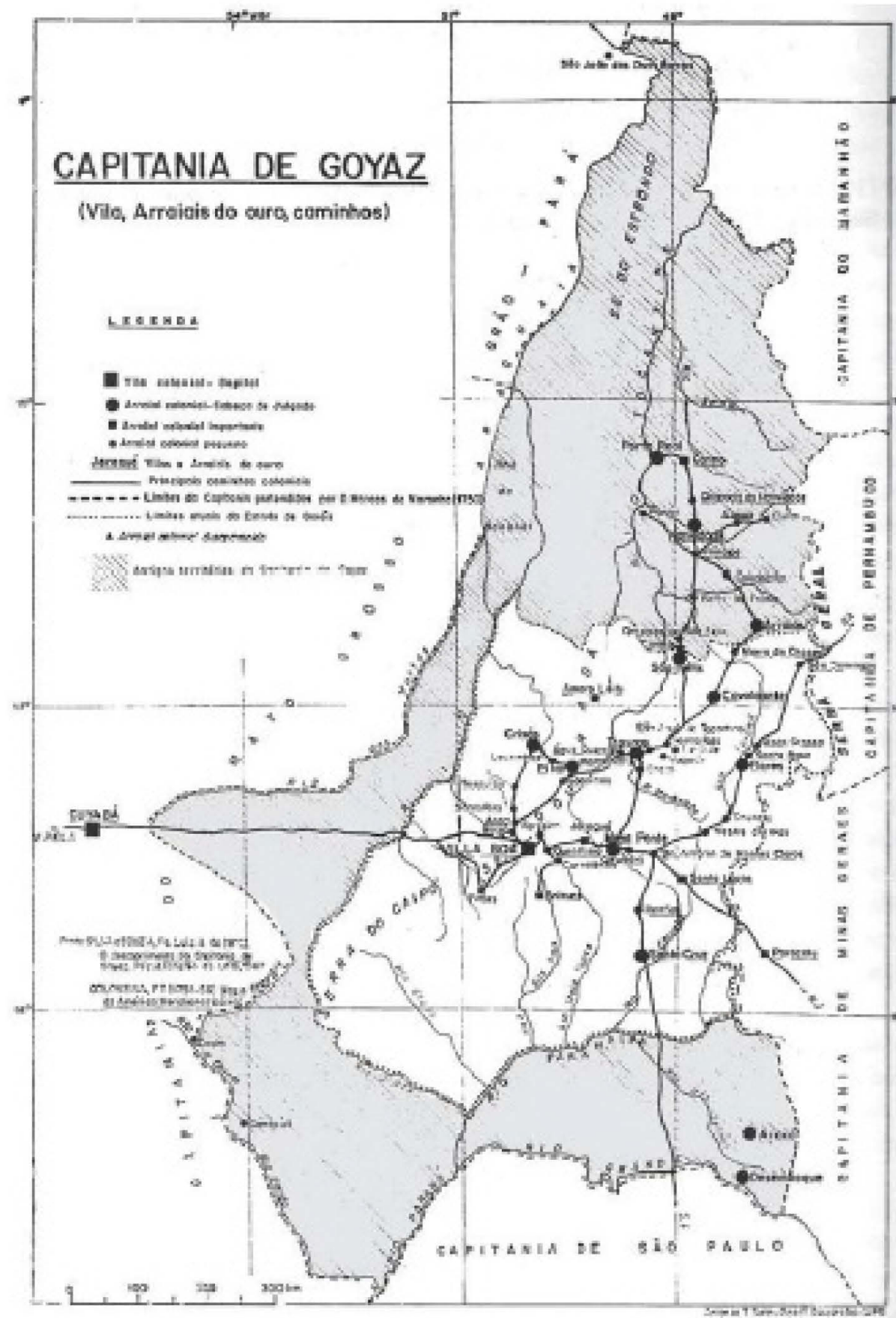

Fuente: TEIXEIRA NETO, A. In: PALACIN, L.; GARCIA, L.; AMADO, J. (1995, p. 44). 
Otro documento, titulado Noticia geral da Capitania de Goiás em 1783 (apud PALACIN; GARCIA; AMADO, 1995, p. 47), trae una descripción detallada de Vila Boa como capital de la Capitanía de Goiás: ubicación, edificios, cuartel, compañía y monumentos. Según los autores, es la más antigua descripción preservada de los campamentos goianos: "escrito en cumplimiento de la orden real de 1782, ordenando a los concejales de los ayuntamientos del reino que apunten, en orden cronológico, los hechos más notables que sucedan" (PALACIN; GARCIA; AMADO, 1995, p. 39). El documento contiene descripciones de iglesias, capillas, cuarteles, y otros, con fecha del año 1783. A continuación, se presenta una breve descripción de informaciones concernientes a datos toponímicos, referentes a los arraiais de la época, que se encuentran en el documento:

“[...] El primer arraial, llamado Barra, por entrar en este lugar el río Bugres en el Vermelho, está a cinco leguas de distancia de esta Vila [Boa], tiene una capilla de Nossa Senhora do Rosário, filial del pueblo. $[\ldots]^{\prime \prime}$

“[...] Anta, llamado así porque la primera cosa más notable que sucedió allí, antes de que su oro fuera patente, fue matar a un tapir allí. [...]"

“[...] Arraial de Crixás se llama así porque los gentíos de este nombre viven allí. [...]"

"[...] Arraial de Pilar, anteriormente Papuam, porque esa tierra estaba cubierta por esta hierba, o pasto, cuando se descubrió. [...]"

“[...] Arraial de Água Quente, así llamado porque a un lado tiene una cachimba, en una situación que horroriza la investigación de sus cuevas. El lago en el medio es muy profundo y, a tientas, se piensa que es muy irregular, ya que se percibe que tiene altibajos. Esta agua sale caliente y se forma un gran arroyo desde el lago. Toda esta agua es salobre y huele mal. [...]"

“[...] Arraial de Traíras se llama así porque en su gran arroyo se han encontrado muchos peces de este nombre. [...]"

"[...] Arraial de São José do Tocantins, se cree que se llama así porque está cerca del río Tocantins, a pesar de que está a diez leguas de él. Es una parroquia de San José, con una hermandad y Capilla del Senhor dos Passos, privilegiada por el Papa Clemente XIII. [...]"

"[...] Arraial de São Félix, anteriormente llamado Carlos Marinho, quien fue el descubridor en el año 1736. [...]" 
“[...] Arraial de Cavalcante, muchos quieren que se haga llamar T. Cavalcante, quien era dueño de una hacienda allí. [...]"

"[...] Arraial de Arraias, llamado así porque en su arroyo que forma una barra en el río Paranã abundaba esta variedad de peces. [...]"

“[...] Arraial Meia Ponte, llamado así por estar en un arroyo de este nombre, establecido por las primeras personas que vinieron a este continente. [...]"

“[...] Arraial Ferreiro, llamado así porque, después de que sus primeros colonos lo dejaron por sus intereses, se quedó allí un herrero con su tienda $[\ldots] "$

"[...] Arraial de Santa Luzia. Los devotos de la Santa lo llamaban así, [...]" (Noticias generales de la Capitanía de Goiás en 1783, Río de Janeiro: Biblioteca Nacional, Biblioteca Nacional, Seção de Manuscritos, Códice 16.3.2. apud PALACIN; GARCIA; AMADO, 1995, p. 39).

El viajero alemán Johann Emmanuel Pohl, que recorrió la Provincia de Goiás en la primera mitad del siglo XIX, también teje algunos comentarios respecto a aldeas y villas por él visitadas:

Julgado de Traíras - “Traíras toma su nombre del río y de los peces que en él se pescan. Este pez, una especie de bagre (Silurus), pesa de 6 a 8 kilos, tiene pocas espinas y es muy sabroso" (POHL, 1976, p.193).

Arraial de Cavalcante - "El Arraial de Cavalcante toma su nombre de los indios que una vez habitaron esta región, hoy totalmente extintos" [...] (POHL, 1976, p. 280).

Arraial de Arraias - "El pequeño Arraial de Arraiais, que toma su nombre del Rio Arraias, está rodeado de sierras y construido en una colina" (POHL, 1976, p. 277). 


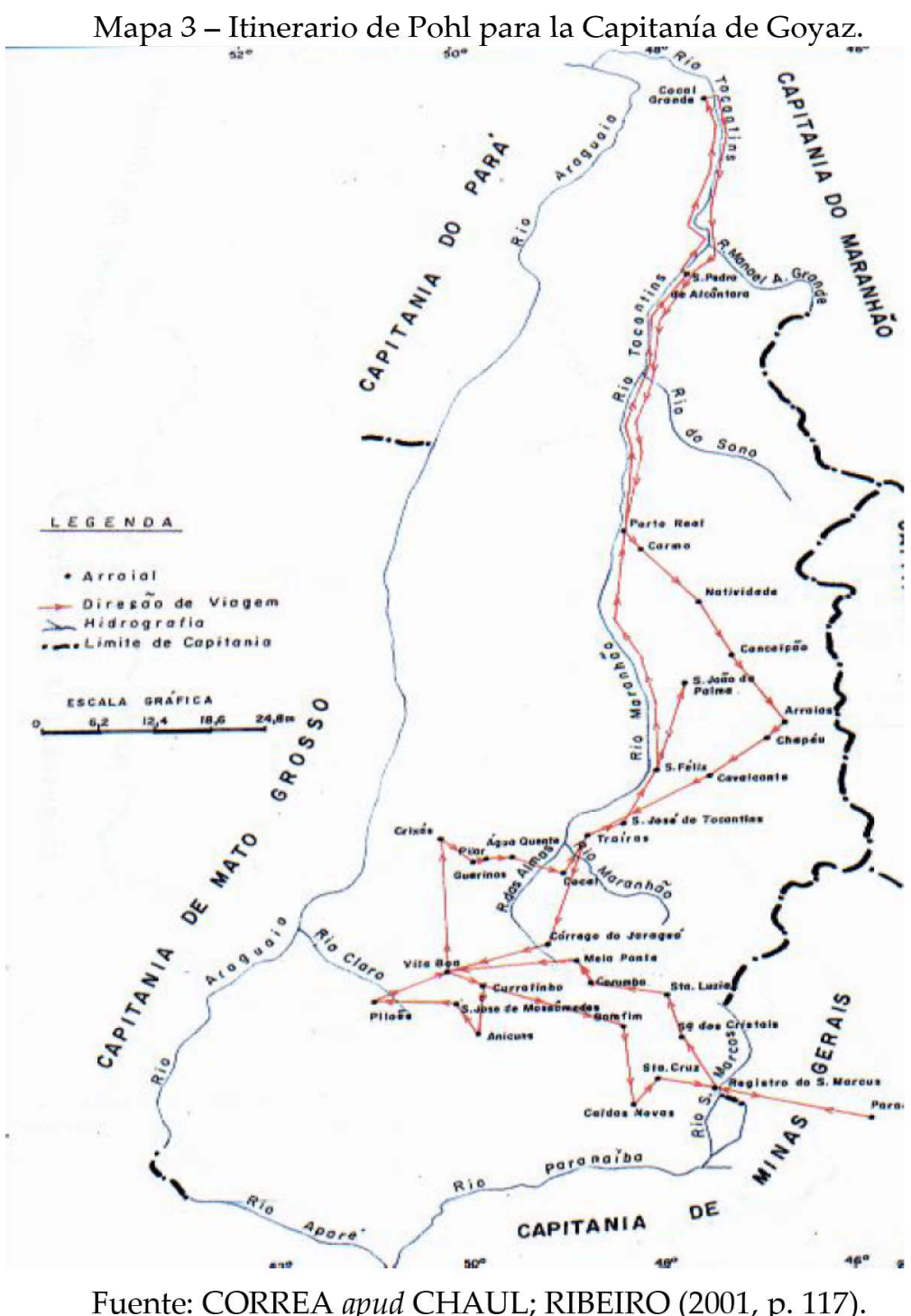

Del topónimo Santa Luzia, citado por Palacin, Garcia y Amado (1995, p.39) en el documento Noticia Geral da Capitania de Goiás de 1783, Casal (1845) reitera la motivación de orden religioso: “El mediocre y próspero pueblo de Santa Luzia, al que dio nombre la patrona de la matriz, que lo adorna [...]" (p. 293) (subrayado nuestro).

Otro campamento citado por Saint-Hilaire fue Ouro Fino. Dice que "el pueblo, que nunca tuvo importancia, debe su origen al oro que una vez fue extraído de Rio Vermelho, y su nombre a la buena calidad de ese oro" (SAINT-HILAIRE, 1975, p.48) (subrayado nuestro). Casal (1845, p.279) corrobora la misma versión, con la diferencia de que la grafía es alterada para Oiro-Fino. 
Acerca de la Aldeia de São José de Mossâmedes, Saint-Hilaire (1975, p. 62) cuenta que el nombre es dado en homenaje al capitán-general José de Almeida, Barão de Mossâmedes. Pohl (1976, p.152), en 1821, recorrió el pueblo y describió la situación de decadencia en que se encontraba. En la descripción, identificamos referencias toponímicas:

La Aldeia de São Iosé de Mossâmedes, lleva el nombre de su fundador, el gobernador general Barão de Mossâmedes, fue erigida en 1755, con un gasto de 67:346\$066. En el año 1780 se construyó la iglesia. La aldea estaba destinada a alojar a las tribus Acroás, Javaés y Carajás, que habían sido traídas allí desde Duro (POHL, 1976, p.152) (subrayado nuestro).

George Gadner (1975), otro viajero que recorrió la Provincia de Goiás, menciona informaciones concernientes al nombre Arraial da Chapada: "[...] fui a Arraial da Chapada varias veces, a unas dos leguas al Noroeste; tiene aproximadamente la mitad del tamaño de Natividade y se encuentra en tierras bajas y planas, que se llaman mesetas y de ahí el nombre [...]" (GADNER, 1975, p. 160) (énfasis agregado).

\section{Consideraciones Finales}

El período de la entrada de bandeiras, conducidas sobre todo por los colonos paulistas y las expediciones de jesuitas por los ríos Araguaia y Tocantins fueron un hito en la formación de la toponimia de Goiás. Por donde andaban, los sertanistas denominaban los lugares a partir de elementos físicos (ríos, riachuelos, riberas, sierras, montes etc.) y elementos humanos y culturales (campamentos, pueblos, juzgados, etc.) marcando el paisaje local a fin de fundamentar la producción de una cartografía que les favoreciese alcanzar sus objetivos: apresamiento de indios $\mathrm{y}$, más tarde, la búsqueda por minerales preciosos. Más allá de esa finalidad utilitaria, sentían que realmente se apoderaban de las tierras y de todo lo que había en ellas. En ese proceso 
de dar nombres se valían los colonos tanto de la lengua general y sus signos como de la representación católica ibérica.

Es recurrente el hecho de que cuando los europeos llegaron a la costa brasileña, al inicio del siglo XVI, ya había diversos grupos indígenas con los cuales mantuvieron sus encuentros y enfrentamientos, entre ellos: Tamoio, Tupinambá, Tupiniquim, Tabajara, Goitacaz, Goianaz, Carijó y otros. Fueron ellos los traductores de las primeras informaciones a los colonizadores al respecto de la naturaleza, de otros pueblos, como también de la toponimia local indígena, aunque esa no haya sido aceptada en el primer momento. La tierra "descubierta" era, para el invasor, un gran vacío onomástico a ser rellenado, y lo sagrado fue la primera opción dada a las órdenes de la Corona y de la hegemónica Iglesia Católica.

Este vacío onomástico inicial pronto da paso a una toponimia detallada que combina la lengua indígena y los nombres de los santos de preferencia ibérica. Es esta mezcla el resultado de una fuerte presencia en el proceso de colonización, marcada por la frontera de las poblaciones ibéricas y los pueblos indígenas en situaciones de conflicto y conformación, lo que resultó en un mapa toponímico con las características de la cultura brasileña. En cierto momento, prevaleció el nombre dado por la tradición cultural indígena; en otro, la ibérica, en el ejercicio constante de establecer las bases civilizadoras ibéricas en este lado del Atlántico. Cuanto más tierra adentro y fronterizas las regiones, mayores son los conflictos y las conformaciones que movieron los procesos de territorialización y las consecuentes construcciones toponímicas, como es el caso de Goiás, actualmente Tocantins.

\section{Referencias}

Arquivo Histórico Ultramarino, CU_013, Cx. 1, D. 67. Disponível em: http://actd.iict.pt/eserv/actd:CUc013/CU-Para.pdf. Acesso en: 28 maio 2015.

BRANDÃO, A. J. da C. (1845). Almanach da Província de Goyaz: para o ano de 1886. Goiânia: UFG; 1978. 
CASAL, M. A. de. Corographia brasílica. 2. ed. Tomo I. Rio de Janeiro: Impressão Régia, 1845.

CASTRO, E. Ensaios da geografia linguística. São Paulo: Cia Editora Nacional, 1941.

CÓDICE COSTA MATOSO. Coleção das notícias dos primeiros descobrimentos das minas na América que fez o doutor Caetano da Costa Matoso sendo Ouvidor- geral do Ouro preto, de que tomou posse em fevereiro de 1749 e vários papeis. 2 vol. Belo Horizonte: Fundação João Pinheiro, 1999.

CORRÊA, M. M. da S. Naturalistas e viajantes estrangeiros em Goiás (1800-1850). In: Goiás: identidade, paisagem e tradição. Goiânia: Ed. da UCG, 2001. p 75-121.

FERREIRA, M. R. O Mistério do ouro dos martírios. São Paulo: Gráfica Biblos, 1960.

FLORES, K. M. Caminhos que andam. O rio Tocantins e a navegação fluvial nos sertões do Brasil. Goiânia: PUC, 2009.

GARDNER, G. Viagem ao interior do Brasil, principalmente nas províncias do Norte e nos distritos do ouro e do diamante durante os anos de 1836-1841. Tradução Milton Amado. Belo Horizonte/São Paulo: Ed. Itatiaia/EDUSP, 1975.

PALACIN, L.; GARCIA, L. F.; AMADO, J. História de Goiás em documentos. I Colônia. Goiânia: UFG, 1995.

POHL, J. E. Viagem no interior do Brasil. Tradução Milton Amado e Eugênio Amado. São Paulo: EDUSP, 1976.

SAINT-HILAIRE, A. de. Viagem à província de Goiás. Tradução Regina Regis Junqueira. Belo Horizonte/São Paulo: Ed. Itatiaia/EDUSP, 1975.

SAMPAIO, T. O tupi na geografia nacional. 5. ed. Corrigida e aumentada. São Paulo: Ed. Nacional, 1987.

SOUZA, L. A. da S. Memória sobre o descobrimento, governo, população e coisas mais notáveis da capitania de Goyaz. Goiânia: Ed. Oriente. p. 126-127, 1978.

VIEIRA, A. Cartas do Padre Antonio Vieira Da Companhia de Jesus. Tomo Terceiro Dedicado ao Eminentissimo, e Reverendissimo Senhor D. Thomas de Almeida Cardeal da Santa Igreja de Roma, Patriarcha I. de Lisboa, \&c. Pelo Padre Francisco Antonio 
Monteiro, Bacharel formado na faculdade dos Sagrados Canones. Lisboa: Na Regia Officina Sylviana, e da Academia Real, M. DCC. XLVI, 1746.

VIEIRA, A. Cartas do P. Antonio Vieyra da Companhia de Jesus. V. 1. ed. Lisboa: Officina da Congregação do Oratorio, 1735 Recuperado de: http://www.brasiliana.usp.br/bbd/handle/1918/01950810. 